\title{
Bile Duct Injury after Cholecystectomy: Surgical Therapy
}

\author{
Bernhard W. Renz Florian Bösch Martin K. Angele \\ Department of General, Visceral, Vascular and Transplantation Surgery, Ludwig-Maximilians-University (LMU) Munich, Munich, Germany
}

Keywords

Bile duct injury · Cholecystectomy · Surgery

\section{Summary}

Background: latrogenic bile duct injuries (IBDI) after laparoscopic cholecystectomy (LC), being one of the most common performed surgical procedures, remain a substantial problem in gastrointestinal surgery. The most important aspect regarding this issue is the prevention of IBDI during index cholecystectomy. Once it occurs, early and accurate diagnosis of IBDI is very important for surgeons and gastroenterologists, because unidentified IBDI may result in severe complications such as hepatic failure and death. Laboratory tests, radiological imaging, and endoscopy play an important role in the diagnosis of biliary injuries. Methods: This review summarizes and discusses the current literature on the management of IBDI after LC from a surgical point of view. Results and Conclusion: In general, endoscopic techniques are recommended for the initial diagnosis and treatment of IBDI and are important to classify them correctly. In patients with complete dissection or obstruction of the bile duct, surgical management remains the only feasible option. Different surgical reconstructions are performed in patients with IBDI. According to the available literature, Roux-en-Y hepaticojejunostomy is the most frequent surgical reconstruction and is recommended by most authors. Long-term results are most important in the assessment of effectiveness of IBDI treatment. Apart from that, adequate diagnosis and treatment of IBDI may avoid many serious complications and improve the quality of life of our patients.

(c) 2017 S. Karger GmbH, Freiburg

\section{Introduction}

Cholecystectomy is one of the most frequently performed procedures in gastrointestinal surgery, and the laparoscopic approach is now the gold standard for symptomatic cholecystolithiasis as well as for chronic and acute cholecystitis [1]. Besides the advantages of a distinctly faster recovery and better cosmetic results, the laparoscopic approach bears a higher risk for iatrogenic bile duct injury (IBDI) and injury of the (right) hepatic artery. IBDI is a complication associated with significant perioperative morbidity and mortality, reduced long-term survival and quality of life, and high rates of subsequent litigation [2]. Despite increasing experience and progress in laparoscopic skills of surgeons, the incidence of IBDI is still elevated compared to open cholecystectomy [2]. The rate of clinically relevant bile leaks after conventional open cholecystectomy ranges between 0.1 and $0.5 \%$ [3-6]. In contrast, biliary leakages have increased in the era of laparoscopic cholecystectomy (LC) by up to $3 \%$ [7-10]. A variety of injuries can occur. Besides minor bile leakage of aberrant ducts, cystic stump or the main bile duct, complete occlusion of the main duct or a branch (often an aberrant right duct) can happen. In addition, bile duct strictures and biliary leakages are severe long-term complications after LC. These injuries are associated with high morbidity, mortality, and prolonged hospitalization [11]. Currently, endoscopic procedures are most frequently used in the management of postoperative IBDI. There are several endoscopic techniques available, e.g. biliary stent placement, biliary sphincterotomy, and nasobiliary drainage [12-14]. In this respect, endoscopic therapy can reduce the transpapillary pressure gradient and improve the transpapillary flow, which decreases the extravasation out of the biliary tract. This reduction of bile leakage allows healing of duct lesion injuries without direct surgical repair. Nonetheless, if major IBDI occurs, i.e. complete dissection of the common bile duct (CBD), surgical management is required to resolve this issue [15]. In an effort to reduce further complications and injuries in the hepatoduodenal ligament, surgical procedures should be performed in collaboration with skilled and experienced hepatobiliary surgeons, interventional radiologists, and gastroenterologists at a tertiary referral center $[16,17]$.

\section{KARGER}

(๑) 2017 S. Karger GmbH, Freiburg

Fax +497614520714
Prof. Dr. med. Martin K. Angele, FACS

Klinik für Allgemein-, Viszeral-, Gefäß- und Transplantationschirurgie

Klinikum der Universität München (LMU) - Klinikum Großhadern

Marchioninistraße 15, 81377 München, Germany

martin.angele@ med.uni-muenchen.de 
Fig. 1. a, b Critical view of safety (CVS).
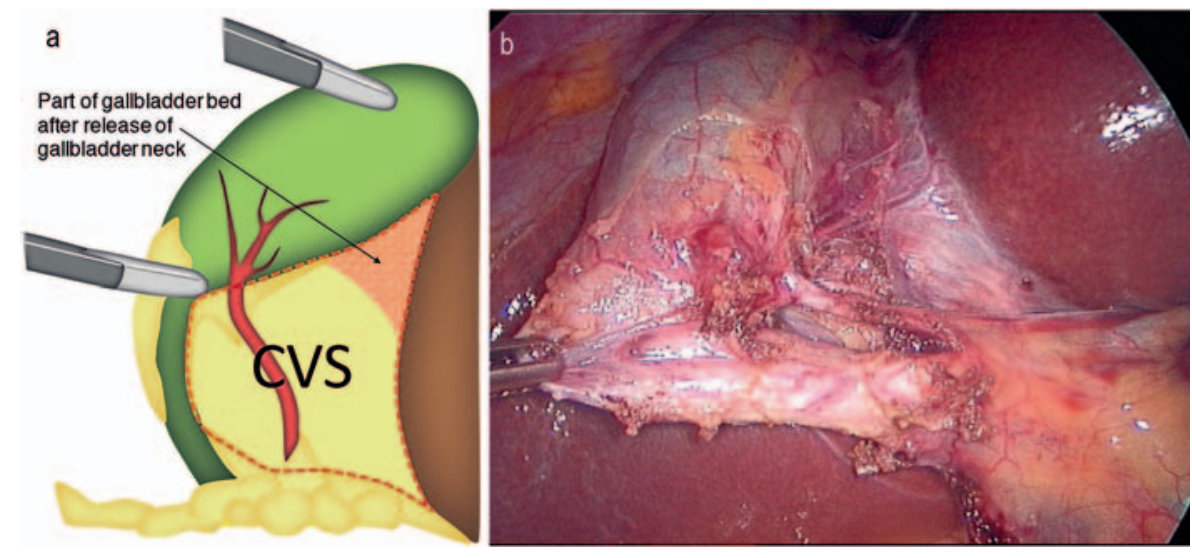

\section{Prevention of Bile Duct Injuries}

Although it has been 25 years since the introduction of LC, as a matter of fact, outcomes remain largely unchanged, with rates of bile duct injury higher in the modern age than in the era of open surgery [18]. Efforts to improve safety in LC have greatly increased the body of knowledge regarding all factors relevant to cholecystectomy. These include timing of the procedure and patient selection [19-22] as well as training and assessment of surgeons performing LC [23]. Endeavors to increase safety of the procedure resulted in optimized intraoperative processes, such as photographic documentation [24] of the 'critical view of safety' (CVS), first described by Strasberg and colleagues almost 20 years ago [25]. Using the CVS technique, the Calot's triangle is completely unfolded by mobilizing the gallbladder neck from the gallbladder bed of the liver. When this view is achieved, the two structures entering the gallbladder (cystic duct and cystic artery) can be definitively detected. Importantly, it is not necessary to see the CBD since such a procedure may disturb bile duct perfusion (fig. 1). In addition to this standard procedure, the use of intraoperative cholangiography (IOC) has been propagated by some institutions [26]. Several additional techniques are described to prevent IBDI during LC. Despite the plethora of publications and debates, there is still no consensus regarding the best setting and method, although most surgeons would agree that the CVS [18] and IOC [27] are among the most popular and effective $[27,28]$. Both of these tools can be used via either laparotomy or laparoscopy. Other methods described include various dissection techniques (infundibular, anterograde, etc.), landmark techniques, Rouvière's sulcus [29], Calot's node [30], or use of ultrasound, just to name a few.

Therefore, the Society of American Gastrointestinal Endoscopic Surgeons (SAGES) has launched a new initiative in order to improve safety in LC, headed by the Safe Cholecystectomy Task Force (SCTF). This task force seeks to encourage a culture of safety in LC and to reduce biliary injury. To elucidate the crucial issues, an expert consensus study was conducted to identify factors considered most important to reach this goal [31]. The following top five most important factors linked to safe practice were denominated: (i) establishing CVS; (ii) understanding of relevant anatomy; (iii) appro- priate retraction/exposure; (iv) knowing when to call for help; (v) recognizing the need for conversion or an alternate procedure (such as subtotal cholecystectomy). However, most of these suggested aspects, even the most widely used, such as CVS and IOC, require initial (blind) opening of the peritoneal layer covering the bile structures and/or cystic plate. In summary, avoidance (prevention) of IBDI requires secure identification of the cystic duct and the cystic artery prior to dissection.

In the future, ultrasound and intraoperative fluorescence cholangiography may help to reduce IBDI. In this respect, near-infrared fluorescence cholangiography (NIRFC) was developed [32-34] and a multicenter randomized controlled trial is currently recruiting to compare NIRFC-assisted laparoscopic cholecystectomy with conventional laparoscopic cholecystectomy (FALCON trial) [35]. When employing this method, intravenous injection of a dye (indocyanine green) and use of specific equipment, i.e. an NIR lightemitting xenon-based light source and a camera that is capable of detecting NIR fluorescence emitted by indocyanine green-dyed bile, is required [36]. Neither the dye (at normal doses) nor the equipment is dangerous (no irradiation) for the patient or surgeon. Compared with IOC, NIRFC has been shown to be quicker to perform and to cost less [37]; however, an increased safety has yet to be proven. Theoretically, it should be possible to perform NIRFC in all cases (vs. a $93 \%$ rate for IOC) because of the impossibility to cannulate the cystic duct (which represents a dangerous risk factor!) $[38,39]$.

\section{Classification of Bile Duct Injuries}

The older classifications are based on peripheral leakages, central leakages, and biliary strictures. Siewert et al. [40] described type 1 lesions, which are peripheral leakages and include immediate biliary fistulas. In contrast, central leakages consist of tangential lesions without structural loss of the bile duct and correspond with type 3 lesions [40]. Type 2 lesions occur when late strictures are diagnosed without obvious intraoperative trauma [40]. Table 1 and 2 present the Corlette-Bismuth classification and the Strasberg classification, respectively. 
The more recently introduced Stewart-Way classification (table 3) incorporates the mechanism of the IBDI as well as its anatomy and has been developed in the era of routinely used laparoscopic surgery. Moreover, this approach is feasible because it provides a tool for prevention of IBDI [41]. The classification also differentiates between resectional injuries and strictures, a distinction which is useful in guiding preoperative evaluation and biliary reconstruction. According to this classification, four types exist (table 3, fig. 2):

- Class I injuries (6\% of cases) occur when the CBD is mistaken for the cystic duct, but the flaw is recognized during the initial operation and before the CBD is transected.

- Class II injuries (24\% of cases) consist of lateral damage to the hepatic duct by unintended application of clips or cautery. These injuries do usually occur when visibility is limited due to inflammation or bleeding. For one reason or another, the surgeon was working too deep in the triangle of Calot, unknowingly close to the common hepatic duct (CHD).

- Class III injuries, the most common (60\% of cases), involve transection and excision of a variable length of the duct, which always includes the cystic duct-common duct junction. Class III injuries result from a misperception error whereby the CBD is mistakenly identified as the cystic duct. The surgeon transects the common duct (deliberately, thinking that it is the cystic duct) early in the dissection and then transects the CHD (unknowingly) later in the process of separating the gallbladder from the liver bed. Consequently, the central portion of the extrahepatic bile duct is removed along with the gallbladder.

- Class IV injuries (10\% of cases) involve damage (transection or injury) of the right hepatic duct (RHD) (or a right sectoral duct), often (60\%) combined with injury to the right hepatic artery (RHA). Class IV injuries are caused either by misidentifying the RHD (or a right sectoral duct) as the cystic duct and the RHA as the cystic artery; or from lateral injury to the RHD (or a right sectoral duct) during the dissection deep in the triangle of Calot. Because the RHA lies posterior to the CBD, it can be injured or even transected in laparoscopic IBDI [42]. This occurrence is particularly common in cases of resectional class IV injury whereby the RHA is thought to be a large cystic artery and is consequently divided.

\section{Diagnosis during Postoperative Period}

Contrary to widespread opinion, the determination of serum alkaline phosphatase and total bilirubin in particular is not sensitive early in the initial postoperative course $[43,44]$. The majority of patients with IBDI will present within the first few weeks following the index operation $[45,46]$. The symptoms will be unspecific and may include fever, pain, and mild hyperbilirubinemia $(2.5 \mathrm{mg} / \mathrm{dl})$ from biloma or bile peritonitis [17]. Biliary leakage will be suspected in the case of bile appearance from either percutaneous drainage of abdominal collection or abdominal drain placed at the time of cholecystectomy. In case of injuries involving occlusion of
Table 1. Corlette-Bismuth classification

\begin{tabular}{cl}
\hline Type 1 & Low CHD stricture, with a length of the CHD stump of $>2 \mathrm{~cm}$ \\
\hline Type 2 & Middle stricture: length of CHD $<2 \mathrm{~cm}$ \\
\hline Type 3 & Hilar stricture, no remaining CHD, but the confluence is preserved \\
\hline Type 4 & $\begin{array}{l}\text { Hilar stricture, with involvement of confluence and loss of } \\
\text { communication between right and left hepatic duct }\end{array}$ \\
\hline Type 5 & $\begin{array}{l}\text { Combined CHD and aberrant RHD injury, separating from the } \\
\text { distal CBD }\end{array}$ \\
\hline
\end{tabular}

$\mathrm{CHD}=$ Common hepatic duct; $\mathrm{RHD}=$ right hepatic duct $\mathrm{CBD}=$ common bile duct.

Table 2. Strasberg classification

\begin{tabular}{ll}
\hline Type A & Bile leak from cystic duct or liver bed without further injury \\
\hline Type B & $\begin{array}{l}\text { Partial occlusion of the biliary tree, most frequently of an aberrant } \\
\text { RHD }\end{array}$ \\
\hline Type C & $\begin{array}{l}\text { Bile leak from duct (aberrant RHD) that is not communicating } \\
\text { with the CBD }\end{array}$ \\
\hline Type D & Lateral injury of biliary system, without loss of continuity \\
\hline Type E & Circumferential injury of biliary tree with loss of continuity \\
\hline RHD = Right hepatic duct; CBD = common bile duct.
\end{tabular}

the $\mathrm{CHD}$ or $\mathrm{CBD}$ without an intraperitoneal bile leak, the main symptoms will be jaundice with or without abdominal pain. In some cases, patients will present with cholangitis or cirrhosis from remote IBDI at a later time, probably months or even years after biliary surgery [25]. In severe early postoperative cases, patients will present with sepsis from cholangitis or intra-abdominal fluid collections. In the case of a suspected bile leak, ultrasound and/or an abdominal computed tomography (CT) scan will identify peritoneal fluid, biloma, or an abscess. In the case of perihepatic fluid collections, drainage can be applied percutaneously. Usually, broad-spectrum parenteral antibiotics covering the common biliary pathogens are initiated [46]. When a percutaneous drainage is applied and ongoing biliary drainage is observed, an active bile leak is verified.

\section{Management}

\section{Principles of Surgical Management}

IBDI can be a very serious complication that, if managed inadequately, can result in life-threatening complications such as cholangitis, secondary biliary cirrhosis (SBC), and portal hypertension. Even with successful management, quality of life may be diminished and survival may be impaired [47]. In general, these injuries are less commonly managed successfully by the primary surgeon who performs the initial cholecystectomy. Biliary reconstruction 
Table 3. Stewart-Way classification

\begin{tabular}{lll}
\hline Mechanism of laparoscopic bile duct injury & $\begin{array}{l}\text { Associated } \\
\text { RHA injury, \% }\end{array}$ \\
\hline Class I & $\begin{array}{l}\text { CBD mistaken for cystic duct, but recognized; } \\
\text { cholangiogram incision in cystic duct extended into CBD }\end{array}$ & 5 \\
\hline Class II & $\begin{array}{l}\text { Lateral damage to the CHD from cautery or clips placed on duct; } \\
\text { associated bleeding, poor visibility }\end{array}$ & 20 \\
\hline Class III & $\begin{array}{l}\text { CBD mistaken for cystic duct, not recognized; } \\
\text { CBD, CHD, RHD, LHD transected and/or resected }\end{array}$ \\
\hline Class IV & $\begin{array}{l}\text { RHD (or right sectoral duct) mistaken for cystic duct, RHA mistaken } \\
\text { for cystic artery; RHD (or right sectoral duct) and RHA transected; } \\
\text { lateral damage to the RHD (or right sectoral duct) from cautery or } \\
\text { clips placed on duct }\end{array}$ & 60 \\
\hline $\begin{array}{l}\text { CBD = Common bile duct; CHD = common hepatic duct; LHD = left hepatic duct; RHA = right hepatic } \\
\text { artery; RHD = right hepatic duct. }\end{array}$ \\
\hline
\end{tabular}

by the primary surgeon results in success rates between 17 and $30 \%$ [41, 48-50]. Data suggest that these injuries should be managed by a hepatobiliary surgeon with extensive expertise in biliary reconstruction as outcomes can be excellent; many expert surgical series report long-term success rates of more than 90\% [51-58]. Given that management of these injuries often requires an experienced multidisciplinary team (including interventional radiology, gastroenterology, and surgery), they are best handled in a tertiary referral center. It can be claimed that if immediate repair is possible by an experienced surgeon, even a completely transected bile duct can be primarily reconstructed as an end-to-end ductal anastomosis by employing simple interrupted absorbable monofilament stitches; this is a well-established routine in liver transplant (LT) surgery. Several conditions must be met for proper healing of each biliary anastomosis. The anastomosed edges should be healthy; there should be no inflammation, ischemia, or fibrosis; and the anastomosis should be tension-free and properly vascularized [59]. Refreshing of the proximal and distal stumps as far as the tissues are healthy and without inflammation should be performed. End-toend ductal anastomosis can be recommended for patients when the maximal loss of length of the bile duct is $4 \mathrm{~cm}$. Approximation of both ends is possible by means of a wide Kocher maneuver. Contradictory meta-analyses regarding the usefulness of a T-tube in LT performing end-to-end ductal anastomosis can be found in the literature $[60,61]$; therefore, the application remains controversial. There is also a second type of T-tube available for biliary drainage, the so-called internal Y-drainage [59]. External T-drainage involves using a typical T-tube with insertion of its short branches into the bile duct, and conducting of its long branch through the abdominal wall outside. It can be removed percutaneously after healing of the end-to-end ductal anastomosis. Internal Y-drainage involves insertion of short branches of the T-tube into both the right and left hepatic ducts, splinting of the anastomosis, and conducting of its long branch into the duodenum by the papilla of Vater. This drainage can be removed endoscopically after healing of the end-to-end ductal anastomosis. It should be emphasized that

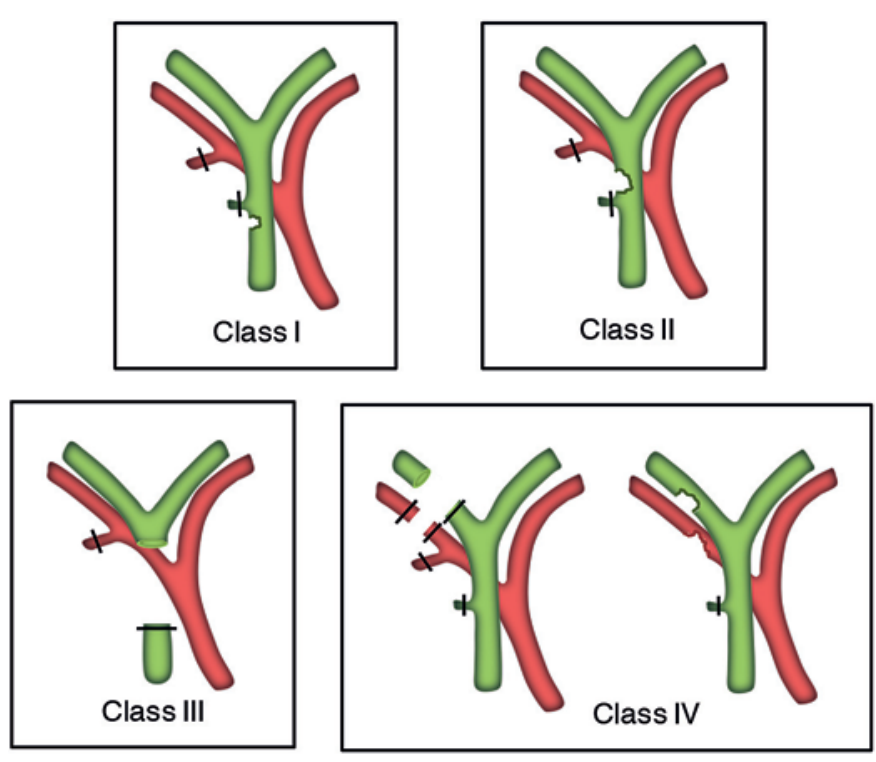

Fig. 2. Stewart-Way classification of laparoscopic bile duct injuries (modified from [41]).

the internal Y-drainage is less traumatic than the external T-drainage as it does not involve additional incision of the bile duct wall. Therefore, it was suggested as the drainage of choice in end-to-end ductal anastomosis [62-64].

In the setting where a two-step approach has to be undertaken because either the injury was not identified at index surgery or an experienced surgeon was not readily available, the goal of surgical repair should be the establishment of a tension-free, mucosa-tomucosa duct enteric anastomosis, which in the majority of the cases will be an end-to-side Roux-en-Y choledochojejunostomy or, more commonly, a Roux-en-Y hepaticojejunostomy. In case of strictures involving the bifurcation or left or right hepatic ducts, bilateral hepaticojejunostomies may be necessary [17]. 


\section{Timing of Biliary Reconstruction}

Several studies reported that the timing of biliary reconstruction influences the outcome; these series reported worse outcomes for biliary reconstructions performed within 6 weeks of injury $[52,54$, 65]. Stewart and Way [48] examined this question, using multivariate analysis, and noted that the timing of repair was not an independent predictor of successful biliary repair. Instead, success correlated with eradication of intra-abdominal infection, complete preoperative cholangiography, use of correct surgical technique, and repair by an experienced biliary surgeon. This timing issue most likely relates to the time required to eradicate intra-abdominal inflammation and to achieve nutritional repletion. In this series, good results were achieved with early biliary reconstruction in those patients with good nutrition, good functional status, and early control of intra-abdominal inflammation [48].

\section{Specific Bile Duct Injuries}

\section{Cystic Duct Leaks}

Cystic duct leaks are well manageable; the treatment of choice is endoscopic retrograde cholangiopancreatography and sphincterotomy [13] or endoscopic stenting and drainage of intra-abdominal bile collections. Nearly all cystic duct leaks will close with this management scheme. It is crucial to drain bile collections; the stent only acts to decrease the pressure in the biliary tree and does neither cover the leak nor prevent bile drainage.

\section{Class I Injuries}

Class I injuries, which are by definition recognized intraoperatively, can be immediately repaired. We recommend fine monofilament absorbable suture (e.g. PDS 6.0). These injuries are usually recognized with cholangiography; thus, only the small incision used to insert the cholangiocatheter needs to be repaired. Insertion of a T-tube catheter is rather contraindicated, as extension of the laceration to facilitate T-tube insertion results in worsening of the injury and an increased risk of stricture [66]. We recommend suturing the incision using simple interrupted stitches.

\section{Bile Duct Injuries Recognized Intraoperatively}

If IBDI other than class I are detected intraoperatively, there are two options. If a senior hepatobiliary surgeon is available, he or she should be called for immediate reconstruction. If not, drains can be placed (to evacuate bile) and the patient should be immediately referred to a tertiary center for further treatment. As already mentioned, repair by the primary surgeon is associated with less favorable outcomes, and sometimes the attempted repair can further damage the ducts and make subsequent reconstruction more difficult [4850]. Surgeons should take into consideration the extent of injury as well as their own experience and skills in biliary surgery when determining the best approach for management of these biliary injuries.

\section{Partial Hepatectomy and Transplantation}

Hepatectomy is rarely required for IBDI; however, in case of failure of reconstructive approaches, it remains a necessary option. The ultimate rescue therapy available would be LT, but the indications are exceptional and reserved for patients in whom liver function is so deteriorated that repair or partial hepatectomy is impossible. These include:

- patients with SBC with associated liver failure, with or without portal hypertension [67-69];

- uncontrolled sepsis of the entire biliary tree, in the presence of severe intrahepatic bile duct strictures or metallic stents [67-69];

- acute liver failure following severe vasculobiliary injury [70-72];

- bile duct injuries in patients with pre-existing chronic hepatic disease [69].

In a small subset of patients with IBDI, failure of surgical or non-surgical management might lead to acute or chronic liver failure necessitating LT. In this regard, over a 24 -year period, Parrilla et al. [73] analyzed 27 patients scheduled for LT with IBDI after cholecystectomy in whom surgical and non-surgical management for IBDI had failed. Emergency LT for acute liver failure was indicated in 7 patients after LC. 2 patients died while on the waiting list and only 1 patient survived more than 30 days after LT. Elective LT for secondary biliary cirrhosis after a failed hepaticojejunostomy was performed in 13 patients after open cholecystectomy and in 7 patients after LC. 1 patient from the elective transplantation group died within 30 days of LT. The estimated 5-year overall survival rate was $68 \%$. In this study, emergency LT for acute liver failure was more common in patients with IBDI after LC and was associated with a poor outcome.

\section{Disclosure Statement}

The authors declare no competing interests.

\section{References}

1 Gallstones and Laparoscopic Cholecystectomy. NIH Consens Statement 1992;10:1-20.

2 Connor S, Garden OJ: Bile duct injury in the era of laparoscopic cholecystectomy. Br J Surg 2006;93:158168.

3 Morgenstern L, Wong L, Berci G: Twelve hundred open cholecystectomies before the laparoscopic era. A standard for comparison. Arch Surg 1992;127:400-403.
4 Gouma DJ, Go PM: Bile duct injury during laparoscopic and conventional cholecystectomy. J Am Coll Surg 1994;178:229-233.

5 Roslyn JJ, Binns GS, Hughes EF, Saunders-Kirkwood K, Zinner MJ, Cates JA: Open cholecystectomy. A contemporary analysis of 42,474 patients. Ann Surg 1993; 218:129-137.
6 Flum DR, Cheadle A, Prela C, Dellinger EP, Chan L: Bile duct injury during cholecystectomy and survival in medicare beneficiaries. JAMA 2003;290:2168-2173.

7 Bailey RW, Zucker KA, Flowers JL, Scovill WA, Graham SM, Imbembo AL: Laparoscopic cholecystectomy. Experience with 375 consecutive patients. Ann Surg 1991;214:531-540; discussion 540-541. 
8 Albasini JL, Aledo VS, Dexter SP, Marton J, Martin IG, McMahon MJ: Bile leakage following laparoscopic cholecystectomy. Surg Endosc 1995;9:1274-1278.

9 Barkun AN, Rezieg M, Mehta SN, et al: Postcholecystectomy biliary leaks in the laparoscopic era: risk factors, presentation, and management. McGill Gallstone Treatment Group. Gastrointest Endosc 1997;45:277282

10 Peters JH, Ellison EC, Innes JT, et al: Safety and efficacy of laparoscopic cholecystectomy. A prospective analysis of 100 initial patients. Ann Surg 1991;213:3-12.

11 Kaman L, Behera A, Singh R, Katariya RN: Management of major bile duct injuries after laparoscopic cholecystectomy. Surg Endosc 2004;18:1196-1199.

12 Chow S, Bosco JJ, Heiss FW, Shea JA, Qaseem T, Howell D: Successful treatment of post-cholecystectomy bile leaks using nasobiliary tube drainage and sphincterotomy. Am J Gastroenterol 1997;92:1839-1843.

13 Llach J, Bordas JM, Elizalde JI, et al: Sphincterotomy in the treatment of biliary leakage. Hepatogastroenterology 2002;49:1496-1498.

14 Kaffes AJ, Hourigan L, De Luca N, Byth K, Williams SJ, Bourke MJ: Impact of endoscopic intervention in 100 patients with suspected postcholecystectomy bile leak. Gastrointest Endosc 2005;61:269-275.

15 Branum G, Schmitt C, Baillie J, et al: Management of major biliary complications after laparoscopic cholecystectomy. Ann Surg 1993;217:532-540; discussion 540-541.

16 Ismael HN, Cox S, Cooper A, Narula N, Aloia T: The morbidity and mortality of hepaticojejunostomies for complex bile duct injuries: a multi-institutional analysis of risk factors and outcomes using NSQIP. HPB (Oxford) 2017;19:352-358.

17 Karanikas M, Bozali F, Vamvakerou V, et al: Biliary tract injuries after lap cholecystectomy - types, surgical intervention and timing. Ann Transl Med 2016;4:163.

18 Strasberg SM, Brunt LM: Rationale and use of the critical view of safety in laparoscopic cholecystectomy. J Am Coll Surg 2010;211:132-138.

19 de Mestral C, Rotstein OD, Laupacis A, et al: Comparative operative outcomes of early and delayed cholecystectomy for acute cholecystitis: a population-based propensity score analysis. Ann Surg 2014;259:10-15.

20 Blohm M, Österberg J, Sandblom G, Lundell L, Hedberg M, Enochsson L: The sooner, the better? The importance of optimal timing of cholecystectomy in acute cholecystitis: data from the national Swedish Registry for Gallstone Surgery, GallRiks. J Gastrointest Surg 2017;21:33-40.

21 da Costa DW, Dijksman LM, Bouwense SA, et al: Costeffectiveness of same-admission versus interval cholecystectomy after mild gallstone pancreatitis in the PONCHO trial. Brit J Surg 2016;103:1695-1703.

22 Tan JKH, Goh JCI, Lim JWL, Shridhar IG, Madhavan K, Kow AWC: Same admission laparoscopic cholecystectomy for acute cholecystitis: is the 'golden 72 hours' rule still relevant? HPB (Oxford) 2017;19:47-51.

23 Aggarwal R, Crochet P, Dias A, Misra A, Ziprin P, Darzi A: Development of a virtual reality training curriculum for laparoscopic cholecystectomy. Brit J Surg 2009;96:1086-1093.

24 Sanford DE, Strasberg SM: A simple effective method for generation of a permanent record of the Critical View of Safety during laparoscopic cholecystectomy by intraoperative 'doublet' photography. J Am Coll Surg 2014;218:170-178.

25 Strasberg SM, Hertl M, Soper NJ: An analysis of the problem of biliary injury during laparoscopic cholecystectomy. J Am Coll Surg 1995;180:101-125.

26 Fletcher DR, Hobbs MS, Tan P, et al: Complications of cholecystectomy: risks of the laparoscopic approach and protective effects of operative cholangiography: a population-based study. Ann Surg 1999;229:449-457.
27 Alvarez FA, de Santibañes M, Palavecino M, et al: Impact of routine intraoperative cholangiography during laparoscopic cholecystectomy on bile duct injury. Brit J Surg 2014;101:677-684.

28 Buddingh KT, Nieuwenhuijs VB, van Buuren L, Huls cher JBF, de Jong JS, van Dam GM: Intraoperative as sessment of biliary anatomy for prevention of bile duct injury: a review of current and future patient safety interventions. Surg Endosc 2011;25:2449-2461.

29 Hugh TB, Kelly MD, Mekisic A: Rouvière's sulcus: a useful landmark in laparoscopic cholecystectomy. Br J Surg 1997;84:1253-1254

30 Ferzli G, Timoney M, Nazir S, Swedler D, Fingerhut A: Importance of the node of Calot in gallbladder neck dissection: an important landmark in the standardized approach to the laparoscopic cholecystectomy. J Laparoendosc Adv Surg Tech 2015;25:28-32.

31 Pucher PH, Brunt LM, Fanelli RD, Asbun HJ, Aggarwal R: SAGES expert Delphi consensus: critical factors for safe surgical practice in laparoscopic cholecystectomy. Surg Endosc 2015;29:3074-3085.

32 Daskalaki D, Fernandes E, Wang X, et al: Indocyanine green (ICG) fluorescent cholangiography during robotic cholecystectomy: results of 184 consecutive cases in a single institution. Surg Innov 2014;21:615-621.

33 Ashitate Y, Stockdale A, Choi HS, Laurence RG, Frangioni JV: Real-time simultaneous near-infrared fluorescence imaging of bile duct and arterial anatomy. J Surg Res 2012;176:7-13

34 Ankersmit M, van Dam DA, van Rijswijk A-S, van den Heuvel B, Tuynman JB, Meijerink WJHJ: Fluorescent imaging with indocyanine green during laparoscopic cholecystectomy in patients at increased risk of bile duct injury. Surg Innov 2017;DOI: 10.1177/1553350617690309.

35 van den Bos J, Schols RM, Luyer MD, et al: Near-infrared fluorescence cholangiography assisted laparoscopic cholecystectomy versus conventional laparoscopic cholecystectomy (FALCON trial): study protocol for a multicentre randomised controlled trial. BMJ Open 2016;6:e011668

36 Boni L, David G, Mangano A, et al: Clinical applications of indocyanine green (ICG) enhanced fluores cence in laparoscopic surgery. Surg Endosc 2015;29: 2046-2055.

37 Dip FD, Asbun D, Rosales-Velderrain A, et al: Cost analysis and effectiveness comparing the routine use of intraoperative fluorescent cholangiography with fluoroscopic cholangiogram in patients undergoing laparoscopic cholecystectomy. Surg Endosc 2014;28:18381843

38 Ishizawa T, Bandai Y, Hasegawa K, Kokudo N: Fluorescent cholangiography during laparoscopic cholecystectomy: indocyanine green or new fluorescent agents? World J Surg 2010;34:2505-2506.

39 Livingston EH, Miller JAG, Coan B, Rege RV: Costs and utilization of intraoperative cholangiography. $\mathrm{J}$ Gastrointest Surg 2007;11:1162-1167.

40 Siewert JR, Ungeheuer A, Feussner H: Bile duct lesions in laparoscopic cholecystectomy (Artice in German). Chirurg 1994;65:748-757.

41 Stewart L: Iatrogenic biliary injuries: identification, classification, and management. Surg Clin North Am 2014;94:297-310

42 Stewart L, Robinson TN, Lee CM, Liu K, Whang K, Way LW: Right hepatic artery injury associated with laparoscopic bile duct injury: incidence, mechanism, and consequences. J Gastrointest Surg 2004;8:523-530; discussion 530-531.

43 Davidoff AM, Branum GD, Meyers WC: Clinical features and mechanisms of major laparoscopic biliary injury. Semin Ultrasound CT MR 1993;14:338-345.
44 Mirza DF, Narsimhan KL, Neto BHF, Mayer AD, Mc Master P, Buckels JAC: Bile duct injury following laparoscopic cholecystectomy: referral pattern and management. Brit J Surg 1997;84:786-790.

45 Lau W-Y, Lai ECH: Classification of iatrogenic bile duct injury. Hepatobiliary Pancreat Dis Int 2007;6: 459-463.

46 Lillemoe KD: Benign post-operative bile duct strictures. Baillieres Clin Gastroenterol 1997;11:749-779.

47 Hariharan D, Psaltis E, Scholefield JH, Lobo DN: Quality of life and medico-legal implications following iatrogenic bile duct injuries. World J Surg 2017;41:90-99.

48 Stewart L, Way LW: Laparoscopic bile duct injuries: timing of surgical repair does not influence success rate. A multivariate analysis of factors influencing surgical outcomes. HPB (Oxford) 2009;11:516-522.

49 Andrén-Sandberg A, Johansson S, Bengmark S: Accidental lesions of the common bile duct at cholecystectomy. II. Results of treatment. Ann Surg 1985;201: 452-455.

50 Carroll BJ, Birth M, Phillips EH: Common bile duct injuries during laparoscopic cholecystectomy that result in litigation. Surg Endosc 1998;12:310-313; discussion 314 .

51 Savader SJ, Lillemoe KD, Prescott CA, et al: Laparoscopic cholecystectomy-related bile duct injuries: a health and financial disaster. Ann Surg 1997;225:268273.

52 Walsh RM, Henderson JM, Vogt DP, Brown N: Longterm outcome of biliary reconstruction for bile duct injuries from laparoscopic cholecystectomies. Surgery 2007;142:450-457

53 Schmidt SC, Langrehr JM, Hintze RE, Neuhaus P Long-term results and risk factors influencing outcome of major bile duct injuries following cholecystectomy. Br J Surg 2005;92:76-82.

54 Thomson BNJ, Parks RW, Madhavan KK, Wigmore SJ, Garden OJ: Early specialist repair of biliary injury. Br J Surg 2006;93:216-220.

55 Walsh RM, Vogt DP, Ponsky JL, Brown N, Mascha E, Henderson JM: Management of failed biliary repairs for major bile duct injuries after laparoscopic cholecystectomy. J Am Coll Surg 2004;199:192-197.

$56 \mathrm{Xu} \mathrm{XD}$, Zhang YC, Gao P, et al: Treatment of major laparoscopic bile duct injury: a long-term follow-up result. Am Surg 2011;77:1584-1588.

57 Mazer LM, Tapper EB, Sarmiento JM: Non-operative management of right posterior sectoral duct injury following laparoscopic cholecystectomy. J Gastrointest Surg 2011;15:1237-1242.

58 Barbier L, Souche R, Slim K, Ah-Soune P: Long-term consequences of bile duct injury after cholecystectomy. J Visc Surg 2014;151:269-279.

59 Jabłonska B: End-to-end ductal anastomosis in biliary reconstruction: indications and limitations. Can J Surg 2014;57:271-277.

60 Sotiropoulos GC, Sgourakis G, Radtke A, et al: Orthotopic liver transplantation: T-tube or not T-tube? Systematic review and meta-analysis of results. Transplantation 2009;87:1672-1680.

61 Huang W-D, Jiang J-K, Lu Y-Q: Value of T-tube in biliary tract reconstruction during orthotopic liver transplantation: a meta-analysis. J Zhejiang Univ Sci B 2011 12:357-364.

62 Jabłonska B, Lampe P, Olakowski M, Górka Z, Lekstan A, Gruszka T: Hepaticojejunostomy vs. end-to-end biliary reconstructions in the treatment of iatrogenic bile duct injuries. J Gastrointest Surg 2009;13:1084-1093.

63 Jabłońska B, Lampe P: Iatrogenic bile duct injuries: etiology, diagnosis and management. World J Gastroenterol 2009;15:4097-4104.

64 Gazzaniga GM, Filauro M, Mori L: Surgical treatmen of iatrogenic lesions of the proximal common bile duct. World J Surg 2001;25:1254-1259. 
65 de Reuver PR, Grossmann I, Busch OR, et al: Referral pattern and timing of repair are risk factors for complications after reconstructive surgery for bile duct injury. Ann Surg 2007;245:763-770.

66 Podda M, Polignano FM, Luhmann A, Wilson MSJ, Kulli C, Tait IS: Systematic review with meta-analysis of studies comparing primary duct closure and T-tube drainage after laparoscopic common bile duct exploration for choledocholithiasis. Surg Endosc 2016;30: 845-861.

67 de Santibañes E, Ardiles V, Gadano A, Palavecino M, Pekolj J, Ciardullo M: Liver transplantation: the last measure in the treatment of bile duct injuries. World J Surg 2008;32:1714-1721.
68 Ardiles V, McCormack L, Quiñonez E, et al: Experience using liver transplantation for the treatment of severe bile duct injuries over 20 years in Argentina: results from a National Survey. HPB (Oxford) 2011;13: 544-550.

69 Lubikowski J, Chmurowicz T, Post M, et al: Liver transplantation as an ultimate step in the management of iatrogenic bile duct injury complicated by secondary biliary cirrhosis. Ann Transplant 2012;17:38-44.

70 Fernández JA, Robles R, Marín C, Sánchez-Bueno F, Ramírez P, Parrilla P: Laparoscopic iatrogeny of the hepatic hilum as an indication for liver transplantation. Liver Transpl 2004;10:147-152.
71 McCormack L, Quiñonez EG, Capitanich P, et al: Acute liver failure due to concomitant arterial, portal and biliary injury during laparoscopic cholecystectomy: is transplantation a valid life-saving strategy? A case report. Patient Saf Surg 2009;3:22.

72 Strasberg SM, Gouma DJ: 'Extreme' vasculobiliary injuries: association with fundus-down cholecystectomy in severely inflamed gallbladders. HPB (Oxford) 2012; 14:1-8.

73 Parrilla P, Robles R, Varo E, et al: Liver transplantation for bile duct injury after open and laparoscopic cholecystectomy. Brit J Surg 2014;101:63-68. 